Vol. 3 No.2 Juni 2020

http://jurnal.umsb.ac.id/index.php/RANGTEKNIKJOURNAL

\title{
Pemanfaatan Teknologi SMS Gateway Untuk Anggota SPP PNPM Mandiri Perdesaan Malai V Suku Pariamanberbasis Web
}

\author{
Nelfira $^{1}$, Tri Apriyanto ${ }^{2}$, Elizamiharti ${ }^{3}$, Icanarwita ${ }^{4}$ \\ Sistem Informasi STMIK Indonesia Padang ${ }^{1,2,3,4}$ \\ Email: nelfira@stmikindonesia.ac.id ${ }^{1}$, triaprianto@stmikindonesia.ac.id², \\ elizamiharti@stmikindonesia.ac.id ${ }^{3}$, icanarwita23@gmail.com ${ }^{4}$ \\ DOI: http://dx.doi.org/10.31869/rtj.v3i2.1849
}

\begin{abstract}
Abstrak:The National Program for Self Empowerment in Rural Areas (PNPM) Malai V Tribe in the SPP (Women's Savings and Loans) group is a special savings and loan program for women in Pariaman. The problems faced by the mirta of delivering information to members, meetings, reminders of the due date of the savings and loan payments for women are still manually, only by telephone, direct notice, and notification by invitation letter, so this method is ineffective and incurs additional costs. In addition, there are often delays in paying installments per month, and this affects the group treasurer, which results in the delay of the treasurer sending financial statements. To overcome these problems an application such as the use of SMS Gateway needs to be created to facilitate rural PNPM Mandiri in delivering information. And in the design of this system using the PHP programming language, Gammu software and MySQL database, and the development method used is SDLC (System Development Life Cycle) with a waterfall model that suits the time and as needed. This study aims to build an application that can help facilitate the process of delivering information to members to improve performance and raise the image and good name of the agency.

Keywords: Technology, SMS, PNPM Gateway, Savings and Loans, Mobile, MySQL
\end{abstract}

\begin{abstract}
Abstrak:Program Nasional Pemberdayaan Masyarakat Mandiri Perdesaan(PNPM) Malai V Suku pada kelompok SPP (Simpan Pinjam Perempuan)adalah suatu program simpan pinjam khusus bagi kaum perempuan di Pariaman. Permasalahan yang dihadapi oleh mitra adalah penyampaian informasi kepada anggota mengenai rapat, pengingat jatuh tempo pembayaran simpan pinjam perempuan masih secara manual, hanya melalui telepon, pemberitahuan secara langsung,dan pemberitahuan melalui surat undangan,sehingga cara ini tidak efektif dan menimbulkan biaya tambahan. Selain itu juga sering terjadi keterlambatan dalam membayar angsuran tiap bulannya, sehingga berdampak kepada kinerja bendahara dan anggota kelompok. Bendahara terlambat membuat laporan dan mengirim laporan keuangan, sedangkan anggota kelompok menunggu antrian untuk meminjam. Untuk mengatasi permasalahan tersebut perlu diciptakan sebuah aplikasi seperti pemanfaatan SMS Gateway untuk mempermudah PNPM Mandiri perdesaan dalam menyampaikan informasi. Perancangan sistem ini menggunakan bahasa pemrograman PHP,perangkat lunak gammu dan database MySQL, dan metode pengembangan yang digunakan yaitu SDLC(System Development Life Cycle) dengan model air terjun (waterfall) yang sesuai denganwaktu dan sesuai kebutuhan. Penelitian ini bertujuan untuk membangun sebuah aplikasi yang bisa membantu mempermudah dalam proses penyampaian informasi kepada anggota meningkatkan kinerja serta mengangkatcitra dan nama baik instansi.
\end{abstract}

\section{Katakunci: Teknologi, SMS, Gateway PNPM,Simpan Pinjam, HP, MySQL}

\section{PENDAHULUAN}

Teknologi informasi salah satu teknologi yang berkembang cepat pada saat ini. Penggunaan alat bantu komputer sebagai salah satu sarana penunjang dalam sistem informasi dapat memberikan hasil lebih baik dan akurat untuk output sebuah sistem,tentu bila sistem didalamnya telah berjalan dengan baik dan sesuai dengan yang diinginkan[1].
Perkembangan teknologi komputer sangatlah pesat, sehingga memudahkan para pengguna dalam melakukan pekerjaannya dalam kehidupan sehari-hari [2]. Selain itu juga dapat mengolah data yang banyak penyampaian atau penyebaran informasi pada semua instansi. Salah satunya yang belum menggunakan komputer secara optimal adalah lembaga 
swadaya masyarakat UPK PNPM Mandiri Perdesaan Malai V Suku Pariaman [3].

Program Nasional Pemberdayaan Masyarakat Mandiri Perdesaan (PNPM) adalah salah satu program pemerintah yang bertujuan untuk menanggulangi kemiskinan dan pemerataan pembangunan khususnya di bidang infrastruktur desa, penambahan permodalan untuk usaha kecil dan pemberdayaan masyarakat [4]. Salah satu kegiatan yang diselenggarakan PNPM Mandiri adalah kegiatan Simpan Pinjam Perempuan [5]. SPP (Simpan Pinjam Perempuan) merupakan suatu program simpan pinjam khusus bagi kaum perempuan berupa dana bergulir yang disalurkan untuk usaha peningkatan kesejahteraan kaum perempuan, kelompok simpan pinjam perempuan ini merupakan perempuan yang melakukan kegiatan produktif untuk pendapatan keluarga dalam rangka mewujudkan keluarga sejahtera. Pada saat ini kegiatan PNPM Mandiri Perdesan pada program simpan pinjam perempuan masih menggunakan sistem manual, belum ada aplikasi khusus yang terkomputerisasi untuk mempermudah UPK PNPM memberikan informasi kepada Anggota Simpan Pinjam Perempuan [6].

Dalam kegiatan menyampaikan informasi kepada anggota PNPM masih minim, khususnya kepada anggota SPP ( Simpan Pinjam Perempuan) selama ini penyampaian informasi rapat dan pengingat jatuh tempo pembayaran angsuran kepada anggota Simpan Pinjam Perempuan PNPM Mandiri Perdesaan Malai V Suku Pariaman hanya melalui telpon, pemberitahuan secara langsung ke rumah anggota, dan pemberitahuan melalui surat undangan yang diantar langsung ke desa oleh staff pusat, sehinggakegiatan yang dilakukan kurang efektif. Penyampaian informasi jatuh tempo dan rapat anggota akan lebih efektif dengan menggunakan aplikasi SMS Gateway,karenadapat mempermudah staff pusat untuk menyampaikan informasi dengan cepat, selain untuk mempermudah staff menyampaikan informasi juga mempermudah anggota dalam mendapatkan informasi secara cepat [7].

Keterlambatan pembayaran angsuran disebabkan kurang disiplinnya anggota dalam pembayaran angsuran pada bendahara UPK dan intensitas kesibukan dari anggota itu sendiri, sehingga sering lupa ketika telah sampai pada masa jatuh tempo pembayaran angsuran, yang berdampak kepada bendahara kelompok SPP (Simpan Pinjam Perempuan) yangmengakibatkan keterlambatan pengiriman laporan keuangan perbulan desa ke bendahara UPK (Unit Pengelola Kegiatan) PNPM. Upaya dalam menanggapi kelancaran pembayaran angsuran dapat dicarikan solusinya dengan menerapkan aplikasi SMS Gateway untuk mempermudah mengingatkan anggota akan tanggung jawab membayar angsuran setiap bulannya, Beberapa peneliti yang sudah melakukan penelitian diantaranya peneliti pertama [8] dengan judul penelitian Pengembangan Sistem SMS Pengaduan Menggunakan SMS Gateway untuk Meningkatkan Kinerja PNPM Mandiri Perdesaan Kabupaten Bulelang Berbasis Web, hasil penelitian merancang Sistem SMS Pengaduan menggunakan SMS Gateway berbasis web.Peneliti kedua,[9] dengan judul penelitian Pembuatan Aplikasi SMS Gateway untuk Informasi Pelayanan Masyarakat di PNPM Perdesaan Kabupaten Pacitan Berbasis web. Hasil penelitiannya merancang aplikasi SMS Gateway untuk informasi pelayanan masyarakat di PNPM perdesana Kabupaten Pacitan Berbasis web yang dapat memudahkan untuk mendapatkan informasi bagi anggota yang akan membutuhkan informasi tentang PMPM tersebut.Peneliti ke tiga [10]dengan judul penelitian Pengembangan Sistem Informasi Pemanfaatan Dana Bantuan Langsung Masyarakat Berbasis Web dan SMS Gateway untuk PNPM Kabupaten Bantul, dengan hasil penelitian Menghasilkan Website dengan memanfatkan SMS Gateway untuk anggota Simpan Pinjam Perempuan PNPM. Berdasarkan beberapa penelitian tersebut dapat disimpulkan bahwa perancangan dan Pengembangan Sistem SMS Gateway untuk Meningkatkan Kinerja PNPM ini memang sangat dibutuhkan oleh pengelola dan untuk anggota PNPM Mandiri Perdesaan Berbasis Web, dan sangat membantu dalam pengolahan data; input data, proses data angsuran, membuat laporan setiap saat.

\section{METODE PENELITIAN}

Metode penelitian merupakan suatu cara atau prosedur dalam mengumpulkan data yang 
diperlukan sehingga data tersebut dapat dianalisa. Adapun metode pengumpulan data yang dilakukan adalah [11]:

\section{Penelitian lapangan (Field Research)}

Melakukan penelitian langsung ke lokasi yaitu UPK PNPM Mandiri Pariaman untuk mendapatkan data primer dengan teknik pengumpulan data sebagai berikut:

Observasi, yaitu pengumpulan data dengan melakukan pengamatan dan disampaikan sebagai dasar dalam merancang sistem informasi yang nantinya akan menunjang pembuatan informasi.

Wawancara, yaitu mengumpulkan data dengan cara komunikasi langsung dengan pihak yang bersangkutan (sumber penelitian) dan didapatkan suatu hasil rancangan dan data-data atau informasi yang nantinya akan menjadi penunjang dalam perancangan suatu sistem.Membuat daftar pertanyaan (quesioner)

Memberikan daftar pertanyaan kepada pimpinan sekaligus bendahara dan juga anggota simpan pinjam perempuan untuk pengolahan data aplikasi SMS Gateway.

\section{Penelitian Pustaka (Library Research)}

Studi pustaka melalui buku-buku, internet atau bahan lainnya yang berkaitan dengan masalah ini yang berguna untuk mendapatkan informasi dan data yang bersifat teoritis.

\section{Penelitian Labor (Laboratory Research)}

Meliputi kegiatan perancangan, pembuatan, pendeteksian kesalahan dan mencoba sistem agar dapat berjalan sesuai dengan yang diharapkan. Spesifikasi komputer meliputi hardware dan software yang sesuai

\section{Metode Pengembangan Perangkat Lunak}

Metode pengembangan perangkat lunak yang digunakan pada penelitian ini adalah metode SDLC(SystemDevelopment Life Cycle) dengan model air terjun (waterfall) atau sering juga disebut model sekuensial linier (sequential liniear). Menurut Hoffer dkk. dalam Kadir (2014) metodologi waterfall adalah suatu proses standar yang diikuti oleh organisasi untuk melaksanakan seluruh langkah yang diperlukanuntuk menganalisis, merancang,

mengimplementasikan, dan memelihara sistem informasi.

System Development Life Cycle, selanjutnya disingkat dengan SDLC, merupakan siklus pengembangan sistem. Pengembangan sistem teknik (engineering system development). SDLC berfungsi untuk menggambarkan tahapan-tahapan utama dan langkah-langkah dari setiap tahapan yang secara garis besar terbagi dalam lima kegiatan utama, yaitu: analisis, desain, implementasi, pengujian, dan pemeliharaan. Setiap kegiatan dalam SDLC dapat dijelaskan melalui tujuan (purpose) danhasil kegiatannya (deliverable). SDLC dalam bentuk Waterfall.Untuk lebih jelas dapat dilihat pada Gambar 1.

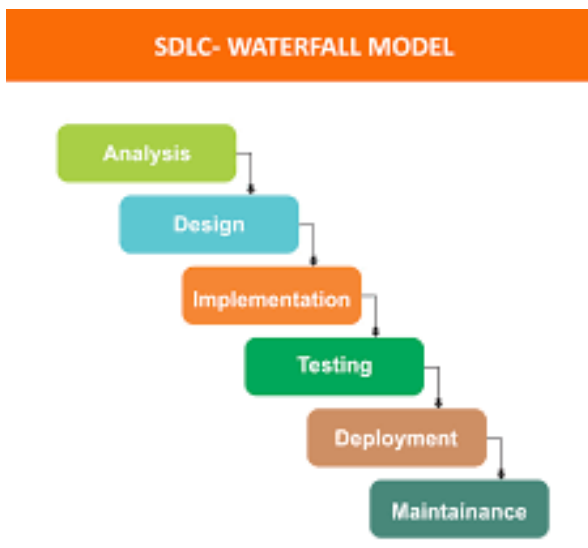

Gambar 1.SDLC dalam bentuk Waterfall.

1. Analisis Sistem

Penelitian dilakukan dengan menganalisis sistem yang sedang berjalan saat ini pada UPK PNPM Mandiri Perdesaan untuk mengetahui permasalahan yang terjadi pada sistem yang sedang berjalan.

Studi KelayakanMenentukan kemungkinan keberhasilan solusi yang diusulkan dengan pembuatan aplikasi SMS Gateway pada kantor UPK PNPM Mandiri Perdesaan Malai V Suku Pariaman yang dapat menyelesaikan masalah yang dihadapi instansi.

Analisis Kebutuhan, Menganalisis sistem yang sedang berjalan dan menentukan kebutuhankebutuhan yang dibutuhkan oleh sistem yang akan diusulkan.

2. Desain Sistem

Mendesain sistem yang baru sesuai dengan masalah-masalah dalam tahap analisis yang telah dilakukan sebelumnya ke dalam bentuk rancangan sistem seperti penggunaan model use case diagram, activity diagram, sequence diagram, class diagram serta flowchart.

Perancangan Konseptual, merancang laporan, rancangan database, menentukan data yang dibutukan dalam pembuatan laporan SMS Gateway.Perancangan Fisik, menentukan 
rancangan platform berupa perangkat keras dan perangkat lunak yang digunakan dalam perancangan database untuk menerapkan aplikasi SMS Gateway untuk menyampaikan informasi dan pemberitahuan jatuh tempo pada anggota Simpan Pinjam Perempuan.

3. Implementasi Sistem

Melakukan implementasi sistem dari sistem aplikasi SMS Gateway yang telah dibuat. Pemrograman dan pengujian. Aktivitas dalam pembuatan program atau sederetan instruksi dalam pembuatan aplikasi penyampaian informasi dan pemberitahuan jatuh tempo pada anggota, pengujian programuntuk menjalankan website dengan menggunakan mozilla firefox dan google chrome dengan perangkat lunak tambahan yaitu Gammu, modem, xampp untuk mengetahui apakah aplikasi yang dirancang telah sesuai atau masih terdapat kesalahan.

Konversi, mengoperasikan sistem baruyaituSMS Gateway untuk menggantikan sistem lama yang dilakukan dengan manual.

4. Pemrogramandanpengujian

Aktivitasdalam pembuatanprogram atau sederetan instruksi dalam pembuatan aplikasi penyampaianinformasi dan pemberitahuan jatuhtempopadaanggota,pengujian program untuk menjalankanwebsitedengan menggunakanmozillafirefoxdan google chrome dengan perangkatlunak tambahan yaitu; Gammu, modem,xampp

\section{Perancangan Sistem}

Perancangan sistem merupakan tahapan setelah menyelesaikan analisis sistem. Pada tahap ini, akan digambarkan bagaimana suatu sistem dapat dibangun dan dapat dipahami proses dan bentuk rancangannya. Pada penelitian ini penulis menggunakan konsep dasar pengembangan sistem SDLC dan digambarkan dengan alat bantu perancangan sistem UML [12]. Perancangan sistem terbagi menjadi dua, yaitu:

Rancangan Global

Rancangan global digunakan untuk mempermudah dalam melakukan rancangan sacara terinci, serta memberikan gambaran tentang hubungan antara sub-sub sistem. Rancangan global juga dapat memberikan kemudahan bagi pemakai dalam mempelajari dan menggunakan aplikasi. Berdasarkan analisis yang dilakukan sebelumnya, maka pemodelan yang digunakan yaitu Unified
Modelling Language (UML) yang mencakup Activity Diagram, Sequence Diagram, Class Diagram serta penggunaan model Entity Relationship Diagram (ERD).

\section{Use Case Diagram}

Use Case Diagram menggambarkan bagaimana seseorang akan menggunakan atau memanfaatkan sistem. Use Case Diagram menggambarkan bagaimana proses-proses yang dilakukan oleh actor terhadap sebuah sistem.Berikut gambar Use Case Diagram yang menggambarkan sistem kerja dalam sistem ini dapat dilihat pada Gambar 2.

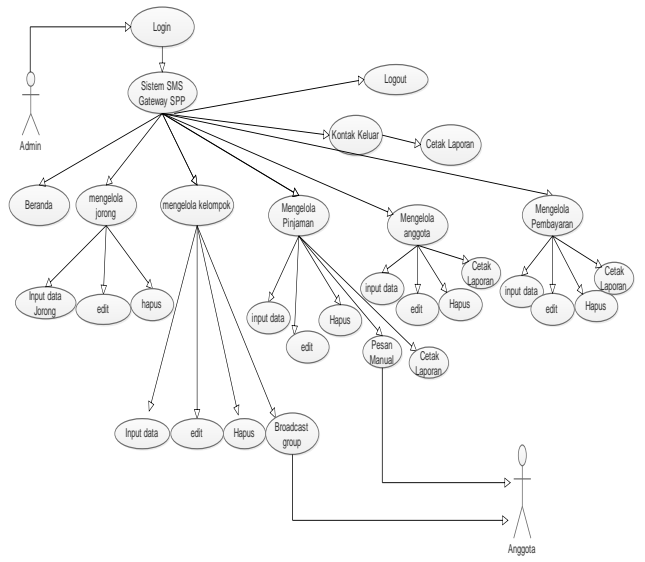

Gambar 2.Use CaseDiagram

Activity Diagram

Aktivitas menggambarkan proses yang berjalan, sementara use case sistem informasi SMS Gateway menggambarkan bagaimana aktor menggunakan sistem untuk melakukan aktivitas. Adapun activity diagram sistem SMS Gateway Simpan Pinjam Perempuan Desa Malai V suku Pariaman adalah sebagai berikut:

\section{Activity Diagram Admin}

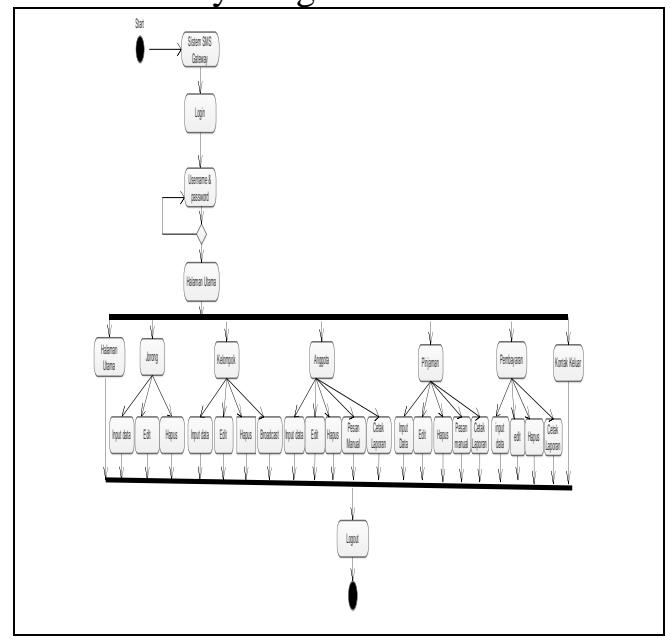

Gambar 3.Activity Diagram Admin 


\section{Sequence Diagram}

Diagram ini menjelaskan bagaimana cara admin menginputkan informasi ke dalam sistem, Adapun Sequence Diagram kelola data informasi dapat dilihat pada Gambar 4.

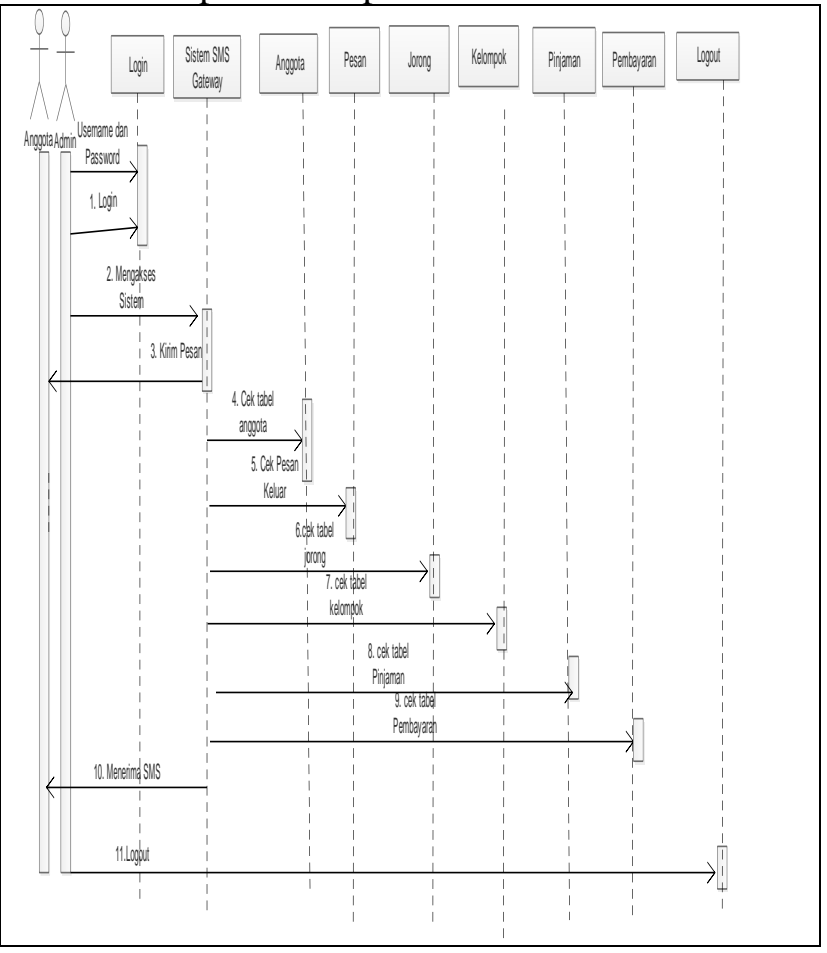

Gambar 4.Sequence Diagram

\section{Class Diagram}

Class diagram adalah sebuah spesifikasi yang jika diinstansiasi akan menghasilkan sebuah objek dan merupakan inti dari pengembangan dan desain berorientasi objek pada sistem SMS Gateway Simpan Pinjam Perempuan Desa Malai V Suku Pariaman.

\section{HASIL DAN PEMBAHASAN}

Setelah melewati proses integrasi dan pengujian (integration and test), maka langkah selanjutnya adalah implementasi program aplikasi. Tahapan implementasi merupakan tahapan pelaksanaan atau penerapan aplikasi SMS Gateway Simpan Pinjam Perempuan PNPM Mandiri Perdesaan Malai V Suku Pariaman, agar dapat digunakan.Adapun bentuk dari implementasi program aplikasi SMS Gateway Simpan Pinjam PerempuanPNPM Mandiri Perdesaan Malai V Suku Pariaman adalah:

Halaman Utama admin

Apabila login benar, maka akan tampil halaman utama untuk administrator. Berikut tampilan halaman administrator dapat dilihat pada Gambar 5.

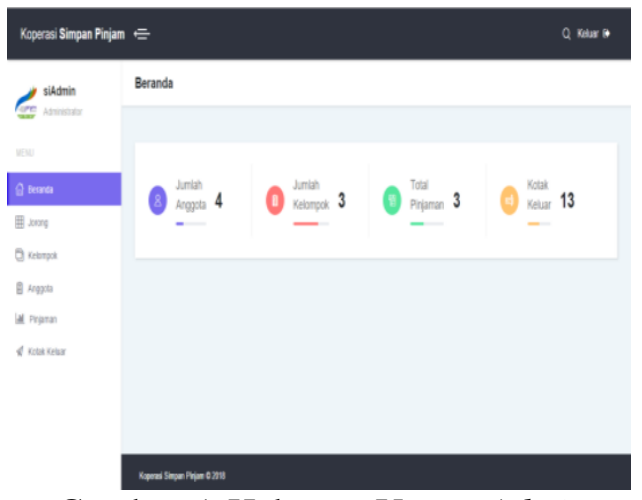

Gambar 5. Halaman Utama Admin

Pada halaman utama ini, admin dapat melakukan berbagai aktifitas yang diinginkannya. Pada halaman ini admin dapat melihat menu beranda, menu jorong, menu kelompok, menu anggota, pinjaman dan kotak keluar. ktifitas-aktifitas yang dapat dilakukan oleh admin tersebut dijabarkan sebagai berikut:

Menu Beranda

Menu beranda merupakan menu memberikan informasi singkat tentang Simpan Pinjam Perempuan PNPM Mandiri Perdesaan Malai V Suku Pariaman, tampilan menu beranda dapat dilihat pada Gambar 6 .

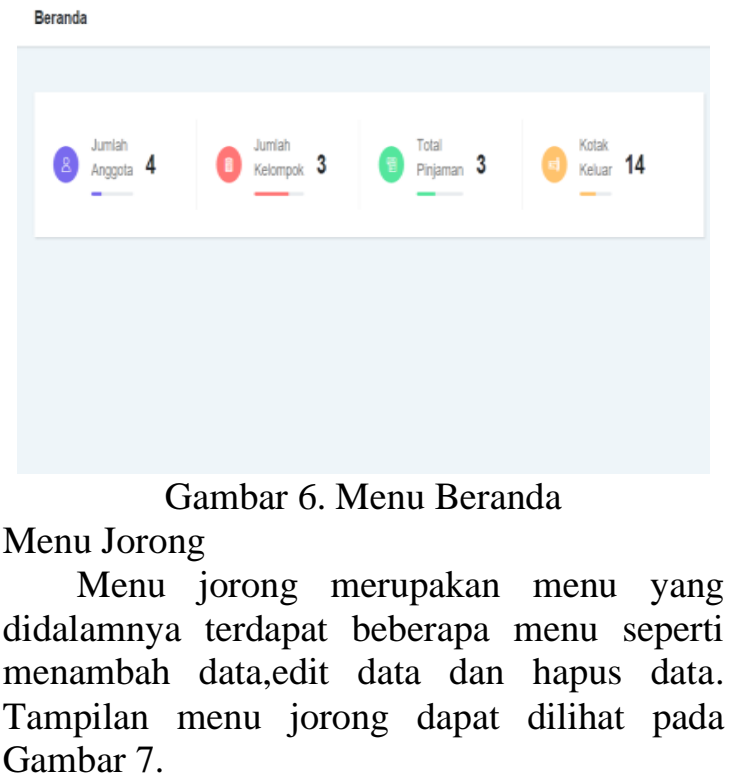




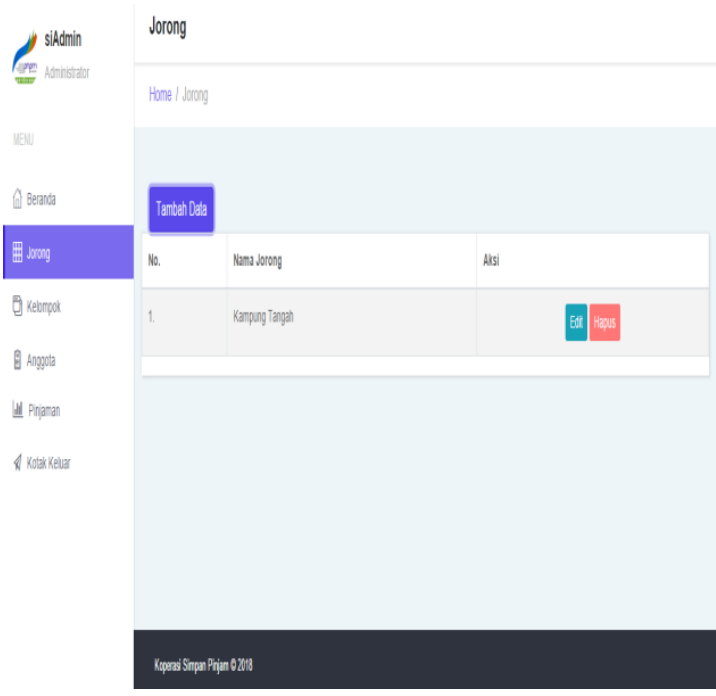

Gambar 7. Menu Jorong

Untuk menambah data jorong dapat menginputkan nama jorong pada kolom tambah data jorong dapat dilihat pada Gambar 8.

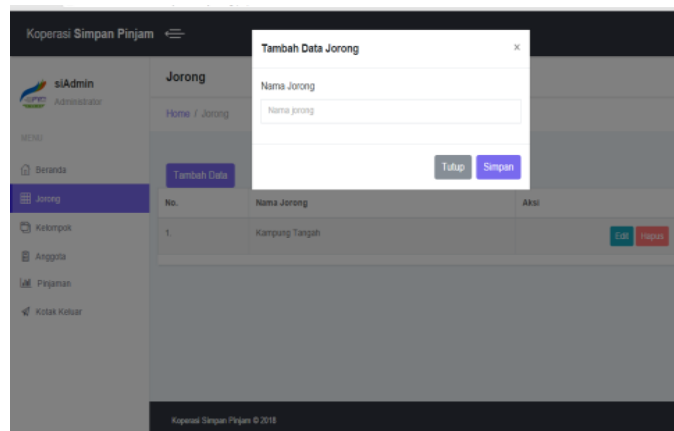

Gambar 8. Menu Input Data Jorong

Menu untuk menginputkan data pesan group pada kolom, admin dapat menambahkan nama kelompok sesuai dengan tujuan kemana pesan yang akan dikirim serta mengisikan pesan pada kolom pesan dapat dilihat pada Gambar 9.

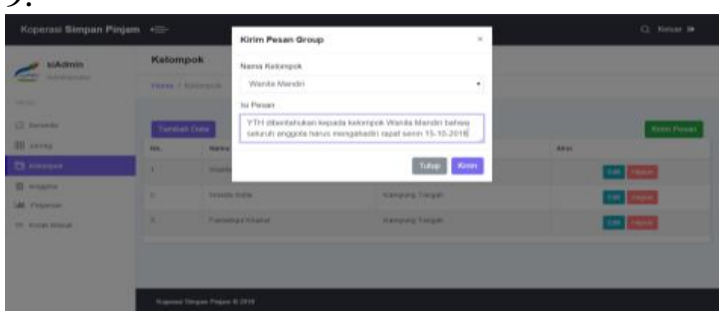

Gambar 9. Kirim Pesan Group

Menu Kelompok

Menu kelompok merupakan menu yang dapat menambahkan data kelompok dan nama jorong dan dapat mengirim pesan group. Tampilan menu kelompok dapat dilihat pada Gambar 10.

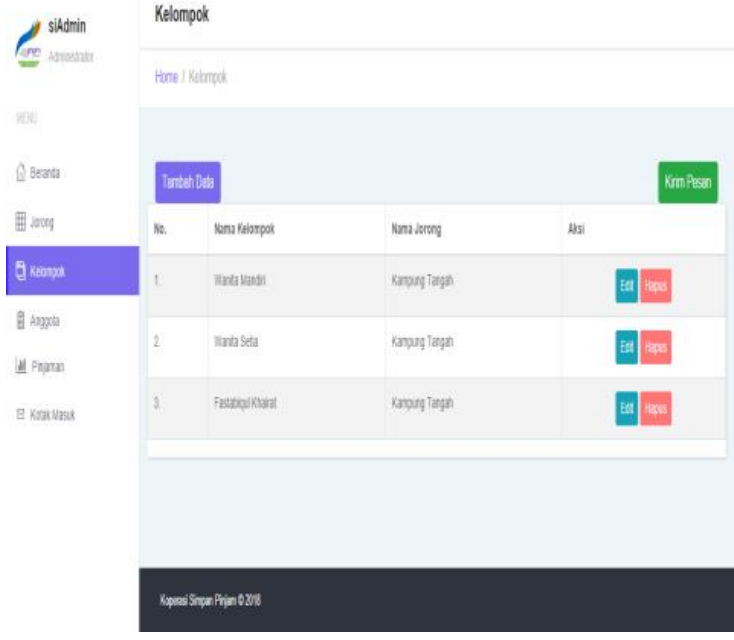

Gambar 10. Menu Kelompok

Untuk menambah data kelompok dapat menginputkan nama kelompok pada kolom tambah data kelompok dapat dilihat pada Gambar 11.

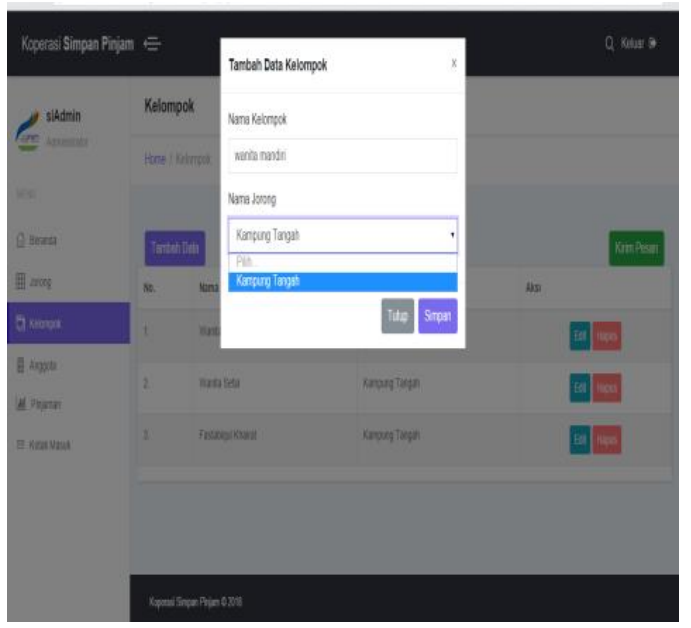

Gambar 11. Menu Input Data Kelompok Menu Anggota

Menu ini merupakan menu untuk input data anggota kelompok dan mencetak laporan dapat dilihat pada Gambar 12.

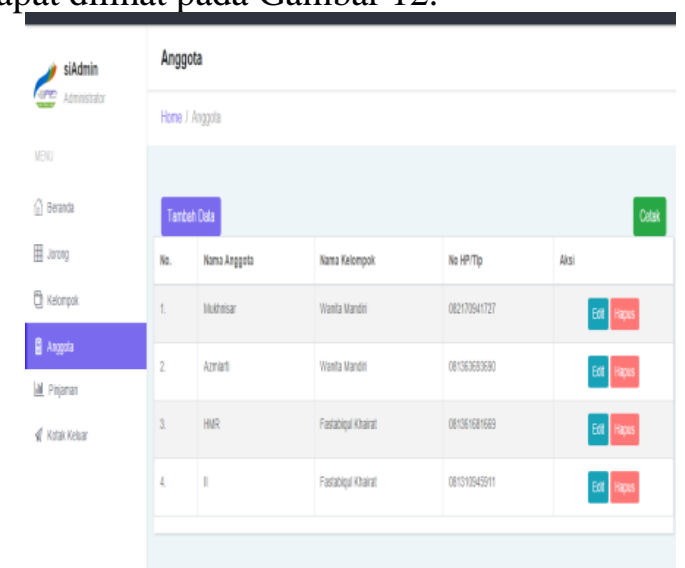

Gambar 12. Menu Anggota 
Menu Pinjaman

Menu Pinjaman merupakan menu untuk menginputkan data yang berhubungan dengan pinjaman dan dimenu pinjaman dapat mengirim pesan manual Tampilan menu pinjaman dapat dilihat pada Gambar 13.

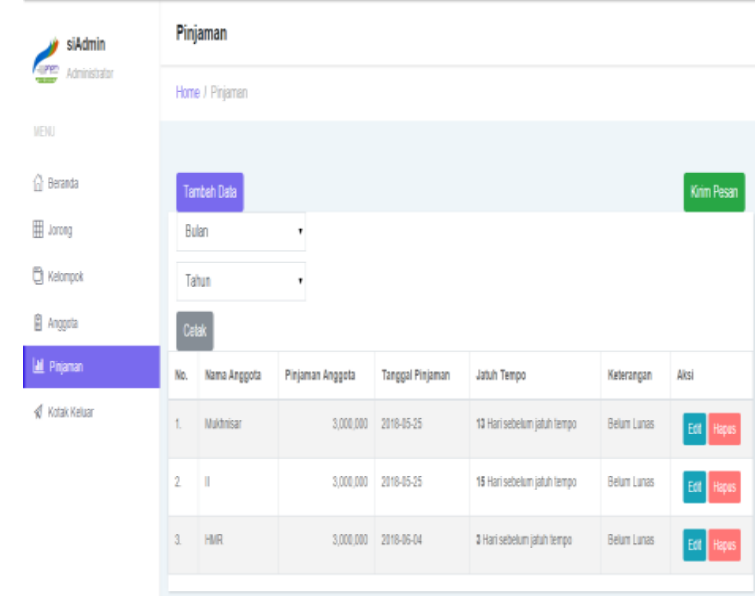

Gambar 13. Menu Pinjaman

Menu untuk menginputkan data pesan manual pada kolom, admin dapat menambahkan nama anggota sesuai dengan tujuan kemana pesan yang akan dikirim serta mengisikan pesan pada kolom pesan dapat dilihat pada Gambar 14.

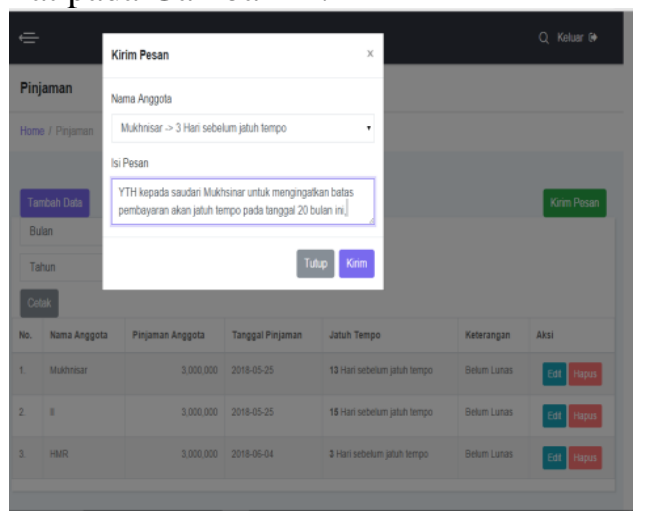

Gambar 14. Kirim Pesan Manual

Menu untuk laporan data pinjaman merupakan rekap data pinjaman yang akan diberikan kepada ketua UPK laporan pinjaman dapat dilihat pada penjelasan dibawah ini:

Menu Pembayaran

Menu Pembayaran merupakan menu untuk menginputkan data yang berhubungan dengan data pembayaran serta merekap data anggota yang terlambat membayar, tampilan menu pembayaran dapat dilihat pada Gambar 15.

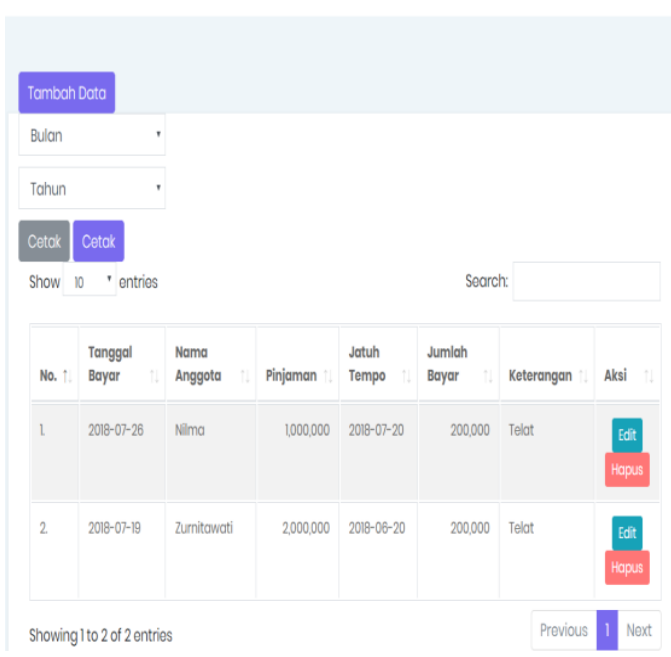

Gambar 15.Menu Pembayaran

Pada menu input pembayaran admin dapat menginput nama anggota, tanggal bayar, dan jumlah anggota membayar input pembayaran dapat dilihat pada Gambar 16.

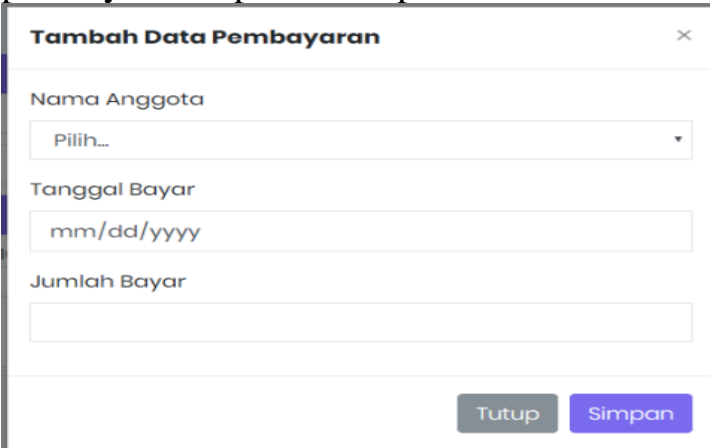

Gambar 16. Menu Input Pembayaran

Menu laporan pembayaran gunanya untuk melihat data-data anggota yang terlambat membayar angsuran.

Menu Kontak Keluar

Menu kontak keluar merupakan menu yang menampilkan pesan yang dikirim dan dapat di cetak.Dapat dilihat pada Gambar 17.

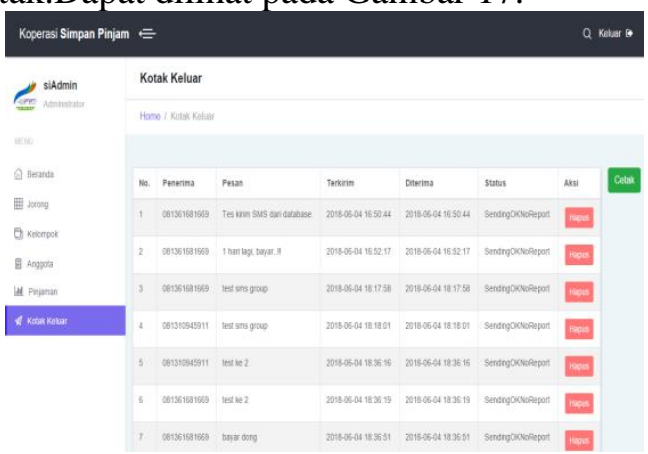

Gambar 17 Menu Kontak Keluar

Menu untuk laporan data kontak keluar merupakan laporan data yang dapat dicetak untuk bukti pengiriman yang diberikan kepada pimpinan dapat dilihat pada Gambar 18 . 


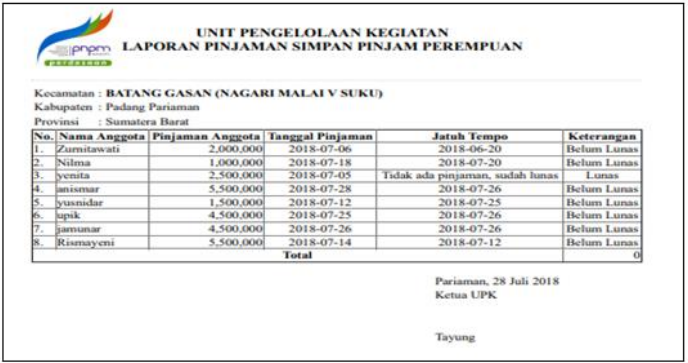

Gambar 18. Laporan Kontak Keluar

Output Pesan Masuk

Merupakan Pesan group dan manual yang diterima oleh anggota, dan dapat dilihat pada Gambar 19.

\begin{tabular}{l|l|}
\hline \multicolumn{1}{|c|}{+6282385486323} & Rincian \\
\hline Hari ini 15.21 Sim7 & \\
\hline selamat pagi diberitahukan \\
kepada seluruh anggota simpan \\
pinjam perempuan mengingat \\
sudah mendekati batas waktu \\
pembayaran diharapkan segera \\
melunasi pembayaran
\end{tabular}

Gambar 19. SMS Broadcast Group Jatuh Tempo

Pesan Broadcast Group rapat merupakan pesan broadcast yang dikirimkan kepada anggota setiap jadwal rapat bulanan, dapat dilihat padaGambar 20.

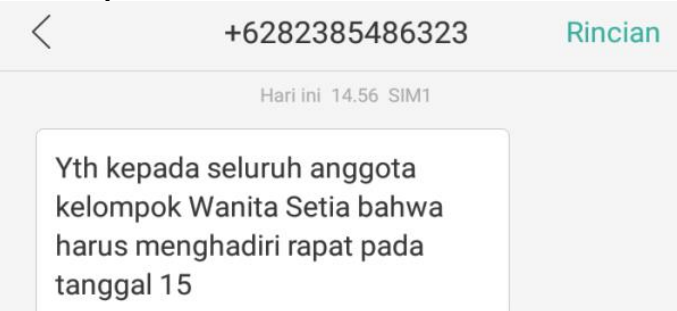

Gambar 20. SMS Broadcast Group rapat

Pesan manual akan dikirimkan kepada anggota yang terlambat membayar angsuran dapat dilihat pada Gambar 21.

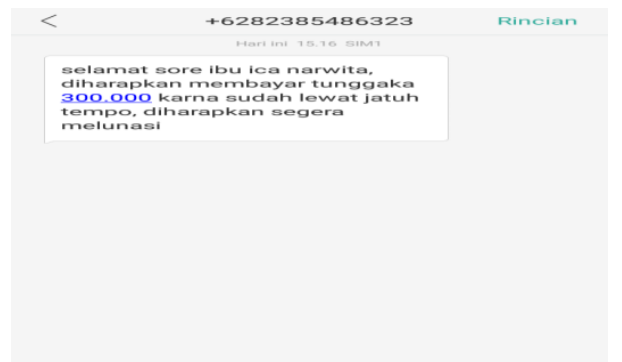

Gambar 21. SMS Manual Jatuh Tempo

\section{PENUTUP}

Berdasarkan hasil dan pembahasan, maka dengan pemanfaatan teknologi SMS Gateway untuk anggota SPP PNPM Mandiri Perdesaan Malai V Suku Pariaman dapat disimpulkan bahwadengan menggunakan SMS Gateway ini stafftidak perlu lagi menelpon anggota satu persatu, sehinggakegiatan yang dilakukan lebih efektif. Sistem yang digunakan ini juga dapat mengingatkan anggota untuk membayar angsuranpinjaman kebendahara, sehingga bendahara UPK tidak terlambat dalam mengirim laporan keuangan.

\section{UCAPAN TERIMA KASIH}

Berisi ucapan terima kasih kepada lembaga LPPM STMIK Indonesia Padang dan juga kepada pimpinan SPP PNPMMANDIRIPERDESAANMALAI V SUKUPARIAMANyang telah membantu dalam pelaksanaan penelitian ini.

\section{DAFTAR PUSTAKA}

[1] A. Cipta, D. Surakarta, J. Ahmad, and Y. No, "Pemanfaatan database Mysql Untuk Proses Komputerisasi Peminjaman Dan Pengembalian alat Laboratorium Di SMK Binawiyata Sragen," J. IT CIDA, vol. 2, no. 1, pp. 67-73, 2016.

[2] T. Loveri, "Sistem Informasi Penyaluran Benih Dinas pertanian Tanaman Pangan Holtikultura Kabupaten Pasaman barat," J. Ilmu Komput., vol. 6, no. 1, pp. 33-39, 2007.

[3] W. Wardiana, "Perkembangan Teknologi Informasi di Indonesia," Fak. Tek. Univ. Komput. Indonesia., 2002.

[4] I. Rosalina, "Efektivitas Program Nasional Pemberdayaan Masyarakat Mandiri Karangrejo Kabupaten Magetan," Fak. Ilmu Sos. dan Huk. 
Univ. Surabaya, vol. 1, pp. 0-216, 2012.

[5] B. M. S. P. P. PNPM Mandiri, D. Muliawati, F. Ekonomi, and I. Lhokseumawe,

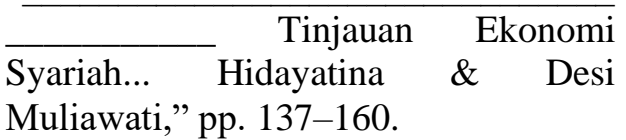

[6] E. Elvayanti, "Sistem Informasi Berbasis Web Pada PNPM Lampung Jurusan Sistem Informasi STMIK PringsewuLampung,"

Www.Stmikpringsewu.Ac.Id, 2009.

[7] H. Murti and H. Listiyono, "Aplikasi SMS Gateway," vol. XIV, no. 1, pp. 30-34, 2009.

[8] P. A. E. Wilantara, I. G. M. Darmawiguna, and M. W. A. Kesiman, "Pengembangan Sistem SMS Pengaduan Menggunakan SMS Gateway Untuk Meningkatkan Kinerja PNPM Mandiri Perdesaan Kabupaten Buleleng Berbasis Web," Karmapati, vol. 3, no. 3, pp. 213-219, 2014.

[9] P. Nasional, P. Masyarakat, K. Tanggamus, and P. Pemerintah, "Rancang Bangun Aplikasi SMS Gateway Untuk Penyampaian Informasi Di Wilayah Kabupaten Tanggamus (Studi Kasus PNPM Kabupaten Tanggamus ) Wahyu Perkasa."

[10] D. A. Saputri, "Pengembangan Sistem Informasi Pemanfaatan Dana Blm ( Bantuan Langsung Masyarakat ) Berbasis Web Dengan SMS Gateway Untuk Kantor PNPM ( Program Nasional Pemberdayaan Masyarakat ) Mandiri Perkotaan Kabupaten Bantul," J. Teknol. Inf., 2014.

[11] I. G. S. Widharma, "Perancangan Simulasi Sistem Pendaftaran Kursus Berbasis Web Dengan Metode SDLC," Matrix J. Manaj. Teknol. dan Inform., vol. 7, no. 2, p. 38, 2017, doi: 10.31940/matrix.v7i2.527.

[12] P. Sulistyorini, "Pemodelan Visual dengan Menggunakan UML dan Rational Rose," J. Teknol. Inf. Din. Vol., vol. XIV, no. 1, pp. 23-29, 2009. 